\title{
Abbaschian Festschrift
}

\author{
Leon L. Shaw $\cdot$ Michael J. Kaufman • \\ Kambiz Vafai
}

Received: 22 May 2011/Accepted: 13 June 2011/Published online: 1 July 2011

(C) Springer Science+Business Media, LLC 2011

\section{Preface}

The planning of a symposium on processing, crystal growth, and phase equilibrium to honor Professor Reza Abbaschian was initiated by Professor Leon L. Shaw at the University of Connecticut in April 2009. Professor Srinath Viswanathan at the University of Alabama and Dr. Yellapu V. Murty at Cellular Materials International enthusiastically agreed to become the conference co-organizers. The ASM Materials Synthesis \& Processing Committee and the TMS Solidification Committee fully supported and approved this conference in October 2009.

Shortly after the approval of the conference, leading scientists and researchers in the areas of processing, crystal growth, and phase equilibrium were invited to give invited presentations in this historic conference in honor of Reza Abbaschian's 40-year contribution to the theoretical and experimental aspects of materials processing, crystal growth, and phase equilibrium. The responses to the invitation and the call for papers were tremendous. As a result, a total of 42 presentations (18 invited and 24 contributed) from researchers and scientists around the world were selected by the organizing committee.

\footnotetext{
L. L. Shaw $(\bowtie)$

Department of Chemical, Materials and Biomolecular Engineering, University of Connecticut, Storrs, CT, USA

e-mail: leon.shaw@uconn.edu

M. J. Kaufman

Department of Metallurgical and Materials Engineering,

Colorado School of Mines, Golden, CO, USA

e-mail: mkaufman@mines.edu

K. Vafai

Department of Mechanical Engineering, University of California at Riverside, Riverside, CA, USA

e-mail: kambiz.vafai@ucr.edu
}

The honorary symposium, entitled "A Symposium in Honor of Professor Reza Abbaschian: Processing, Crystal Growth and Phase Equilibrium of Advanced Materials," was held at MS\&T' 2010 Conference in Houston, TX, October 17-21, 2010. A total of 10 session chairpersons, consisting of the foremost contributors to the fields of materials processing, crystal growth, and phase equilibrium presided and led stimulating discussions. The topics of the symposium covered a wide range of areas to which Professor Abbaschian has made seminal contributions: powder processing, solidification of stable and metastable structures, high pressure-high temperature crystal growth, containerless processing, effects of gravity on crystal growth, phase diagrams, and role of interfaces on the processing and properties of materials.

To further assimilate the significant and lasting impact that Professor Abbaschian has made on the fields of solidification, crystal growth, powder processing, and phase equilibrium, Professor Leon Shaw has served as a guest editor along with Professor Mark Aindow, Editor of Journal of Materials Science, to organize a Festschrift in a special issue of Journal of Materials Science. After a full peerreview according to the usual procedures for Journal of Materials Science, 17 outstanding manuscripts were accepted for publication. These have been grouped in Abbaschian Festschrift according to their fields, starting from solidification theories and ending with powder processing.

We would like to take this opportunity to thank the authors for presenting the papers and the session chairpersons for organizing the sessions and leading the stimulating discussion. We would also like to thank those who have reviewed the papers published in this Festschrift. Finally, we thank Professor Abbaschian for his significant and lasting contributions to the field and for being a mentor, friend, and colleague for so many, including the authors and participants in the conference.

Leon L. Shaw 


\section{A tribute to Professor Reza Abbaschian}

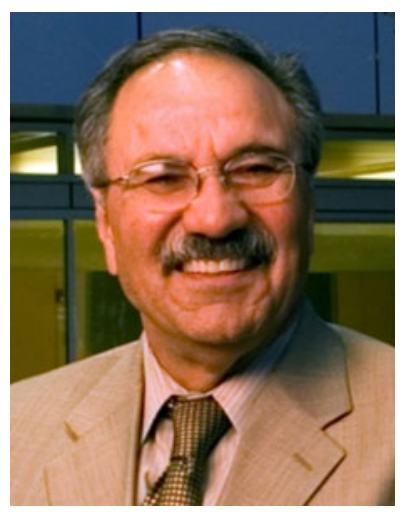

Reza Abbaschian was educated at the University of Tehran, Michigan Technological University, and UCBerkeley where he received his PhD in 1971. He served as visiting assistant professor at the University of Illinois, chairman and professor at the Pahlavi University in Shiraz, Iran, and visiting scientist at MIT. After joining the University of Florida faculty in 1981, he became the department chair in 1986 and became the Vladimir A. Grodsky Professor of Materials Science and Engineering a few years later. As department chair for 16 years, he transformed the MSE department from a good program into a great program. Under Reza's vision and leadership, the MSE faculty grew from around 15 to well over 30, and research funding exceeded $\$ 10 \mathrm{M}$ in many of those years. In addition, student quality continually improved during this period as students from all over the world sought out the UF-MSE program because of its increasingly impressive reputation. This transformation and reputation raised the department's profile so that it skyrocketed into one of the top 10 materials science and engineering departments as rated by U.S. News and World Report. He stepped down as chair when the department tied with his alma mater UC Berkeley for number 6 . The recent NRC ranking, based on data prior to 2005 , ranked the department as number 2 in the nation.

During Reza's tenure as department chair, he was extremely active in professional societies, in particular in TMS and ASM. He tirelessly served on many national committees and educational panels as materials education broadened into new and non-traditional areas of emphasis. He was sought after for his vision of integrated materials education, and he delivered.

In addition to his building the department at Florida, Reza continued his research and teaching with an excellent pace. He is a world renowned expert in the field of solidification processing. He has opened many doors and brought much understanding to both the science and engineering of solidification. His research concentration has been in solidification and materials processing, with projects dealing with interfacial kinetics, containerless processing, phase equilibrium, high temperature intermetallics, composites, and high temperature-high pressure growth of diamond crystals for jewelry applications. His contribution to high temperature-high pressure crystal growth has led to the commercial production of diamond crystals for jewelry applications by Gemesis Corporation. His innovative work on the use of the Seebeck effect to measure solid-liquid interface temperature has resulted in microgravity experiments and growing single crystals on multiple space shuttle flights. His cutting-edge research has led to over 230 scientific publications, four patents, eight patent disclosures, and eight books, including co-authoring of the Third and Fourth Editions of Reed-Hill's classic Physical Metallurgy Principles. Reza's outstanding contributions to the field have earned him numerous awards and distinctions, including TMS Leadership Award for "outstanding leadership in the fields of metallurgy and materials," TMS Structural Material Division's Distinguished Scientist/Engineer Award for "a long lasting contribution to the fundamental understanding of microstructure, properties and performance of structural materials for industrial applications," and ASEE Donald E. Marlowe Award, and Davis Productivity Award of the State of Florida. He was inducted into the elite rank of Fellows of the Minerals, Metals \& Materials Society and ASM International for "outstanding research in the science of solidification and materials processing, for leadership in education, and for extensive contributions to the ASM Phase Diagram program."

In 2005, Reza was recruited by the University of California, Riverside, where he became the William R. Johnson, Jr. Family Professor and Dean of Engineering. In the five-plus years since he became Dean of the Bourns College of Engineering (BCOE) at UC Riverside, he has been recognized for leadership in materials research, and he has guided the growth and development of BCOE to national prominence in several fields. He continues to be one of the world's premier researchers in materials synthesis as well as a successful and effective education leader. In 2005, Reza was named President of the nation's largest materials association, ASM International, and in 2007 he was made a Fellow of the American Association for the Advancement of Science.

One of Reza's earliest accomplishments as dean of BCOE was to establish an interdisciplinary Materials Science and Engineering degree program, which now is thriving. This program integrates across all engineering departments and provides a paradigm shift in materials education. Reza led the establishment of the Southern California Research Initiative in Solar Energy (SC-RISE) in 2009, part of the College's extensive portfolio in 
environmental and energy research and education. The program is connected to some new strategic collaborative alliances, with Tsinghua University in China, Tohoku University in Japan, and Hanyang University in South Korea. In 2011, UCR announced a \$10 million donation by Chinese entrepreneur Winston Chung, which will support a new research initiative in energy storage, among other activities and programs.

Less than a year after arriving at BCOE, Dean Abbaschian led the process for re-accreditation of all of the
College's degree programs, and the first-time accreditation of the Computer Science degree program. As dean, Reza also has been chair of a UCR campus-wide committee on student success. In 2010, the National Research Council ranked five $\mathrm{BCOE}$ degree programs in the top quartile nationally - a significant achievement for a College that is barely 20 years old.

Michael J. Kaufman

Kambiz Vafai 